\title{
The Area Vasta of Cagliari: an Insight into the Real Estate Market Within a Wider Integrated Approach on the Urban Areas Competitiveness Level
}

\author{
Francesca Bodano $^{1, a}$, Luisa Ingaramo ${ }^{2, b}$ and Stefania Sabatino ${ }^{1, c}$
}

${ }^{1}$ DIST (Interuniversity Department of Regional and Urban Studies and Planning), Politecnico Torino (Italy)

${ }^{2}$ SiTI - Higher Institute on Territorial Systems for Innovation, Torino (Italy)

afrancesca.bodano@polito.it, 'luisa.ingaramo@polito.it, c'stefania.sabatino@polito.it

Keywords: Competitiveness-index, Sustainability, Multi-dimensional Analysis, Territorial Analysis Revolving Funds, Real Estate Market.

Abstract. The paper offers a territorial analysis extracted from the 2013 edition of the "Rapporto Annuale di Competitività delle Aree Urbane Italiane" (RCAU) ${ }^{1}$. The Report (IV edition at present) is produced thanks to the commitment of a multi-curricular partnership, supported by the European Bank of Investment, to enhance the strategic knowledge of investors, potentially interested in the European JESSICA initiative.

The insight into the Area Vasta of Cagliari is relevant as it shows the opportunities offered by the competitiveness RCAU standardised analysis model, based on 110 provinces (NUTs ${ }^{2}$ territorial units), to develop further in depth studies on thematic clusters or specific areas. The result is the chance of critically comparing fact-finding information at different geographic scales.

The analysis herewith presented led to highlight some typical cause-effect relations in the Cagliari Area Vasta from the urban towards the rural territory (i.e.: the real estate values distribution depending on the location of material and immaterial infrastructures, even considering the so called "human capital" balance).

In this respect it's remarkable to recall that the housing price tends to capture both intrinsic and extrinsic components, being a good index of territorial competitiveness. One of the advantages of the study is its replicability, thanks to the RCAU dataset ( 80 indicators covering demographic, economic and territorial data), useful to support decision makers in a direct, not strictly technical communication. Among the potential decision makers a pivotal role is currently played in Italy by Banking Foundations. In fact they are at present the main promoters of the RCAU project itself, as they are looking to take advantage of revolving funds ${ }^{3}$ investments to create sustainable and resilient strategies.

\section{Introduction}

The RCAU-Urban Areas Competitiveness Report is a research project aimed at supporting the European initiative called JESSICA (Joint European Support for Sustainable Investments in City Areas [1]. The JESSICA initiative, promoted in 2005 by the European Commission, in partnership with the European Bank for Investments (EIB) and the Council of Europe Development Bank (CEB), relays on revolving funds. In Italy in 2009 a group of banking foundations ${ }^{4}$ committed a

\footnotetext{
${ }^{1}$ Sinloc, Fondazione Ismu, SiTI, Istituto Tagliacarne, "Rapporto di Competitività delle Aree Urbane Italiane 2012”, Padova, Dicembre 2013.

${ }^{2}$ In 1988 Eurostat codified a common comparable definition to address different territorial levels within the European Member States: the NUTs-, Nomenclature des Unités Territoriales Statistiques- depending on three main demographic scales. In Italy we recognise: NUTs 1 ( $3 \mathrm{mln}-7 \mathrm{mln}$ inhab) as "macroregioni”, NUTs 2 (800 thousands - $3 \mathrm{mln}$ inhab.) as "regioni”, NUTs 3 (150 - 800 thousands inhab.) as "province".

${ }^{3}$ They are financial tools aimed to produce sustainable effects in a mid-long term vision. Typically used in local regeneration processes, such as the Jessica funds system.

${ }^{4}$ At present the RCAU promoter foundations are: Compagnia di San Paolo (Turin), Fondazione Cariplo (Milan), Fondazione Cassa di Risparmio Cuneo, Fondazione Cassa dei Risparmi di Forlì, Fondazione Cassa di Risparmio di Fossano, Fondazione Cassa di Risparmio di Gorizia, Fondazione Cassa di Risparmio di Padova e Rovigo, Fondazione Cassa di Risparmio di Parma, Fondazione Cassa di Risparmio Salernitana, Fondazione Cassa di Risparmio di Udine e Pordenone, Fondazione Tercas (Teramo).
} 
cross-curricular partnership (research institutes, foundations, and consultancy companies), to analyse the urban areas competitiveness in order to enhance their potential strategies within the JESSICA initiative ${ }^{5}$.

The research team developed a standardised calculation model useful to catch any competitiveness gap between different Italian areas and published four editions of the RCAU Report so far $[2,3,4,5]$.

Each year the Report provides a specific insight. In 2009 the insight focused on the Piedmont region, in 2010 the Report deepened the housing affordability emergency across Italy, while in 2011 the Sicily Island was analysed. The last edition offers a detailed study on Sardinia Island and the Area Vasta of Cagliari.

Following a brief introduction on the territorial competitiveness issue (section 1), the paper highlights two components: the national macro calculation model and its application on the specific administrative Area Vasta of Cagliari (section 2), which was commissioned by the Sardinia Region and was published in the 2013 Report.

\section{Territorial competitiveness}

An early definition of competitiveness can be traced back to Adam Smith's theory (1776 [6]) of XVIII century, developed in his famous masterpiece "The Wealth of Nations". Smith relates it to the business success. D. Ricardo's theory (1817 [7]) followed, based on the relation between competitiveness and comparative advantages. K. J. Arrow (1962 [8]) and F. A. Von Hayek (1976 [9]) made a significant contribution, suggesting that technological changes can impact on a country's operative results more than expenditures. In these definitions the territorial competitiveness seems to be confined within its strictly economic connotation and does not satisfy any welfare measurement. During last two hundred years the competitiveness issue is deeply changed. In the ' 80 s and ' 90 s of the XX century the term has assumed a wider meaning- see i.e the "Report of the Brundtland Commission" or the "Kyoto Protocol", in which the competitiveness issue started to be considered as the sum of different elements and resources, both material and immaterial. In the light of this vision an urban area can today be defined competitive if it manages to foster virtuous chains among its material or immaterial resources (World Commission on Environment and Development, 1987 [10]; United Nations, 1997 [11]).

According to this definition the RCAU Report tried to select those dimensions addressing advantages and risks to the 110 Italian provinces, in order to get local stakeholders (potential investors and policy makers) used to intervene through the JESSICA revolving funds.

\section{The analysis: from the macro-national dataset to the insight on Cagliari}

The macro RCAU dataset is based on the processing of a wide set of data (i.e. economic, demographic variables, environmental indexes, infrastructural components, real estate indicators and social-cultural factors) through statistical, econometric and forecasting elaborations, covering 110 Italian provinces ${ }^{6}$. The 80 raw variables, selected depending on the data availability and the scale of uniformity ${ }^{7}$, lead, by means of a three level aggregation process. The $1^{\circ}$ level represents the global competitiveness score, the $2^{\circ}$ level gather the 6 main dimensions studied in the analysis (demography, economy, real estate market, environment, infrastructure and society) while the $3^{\circ}$ level, 21 competitiveness indexes, represents an intermediate aggregation of the raw variables within each dimension (see fig. ${ }^{\circ} 1$ ).

\footnotetext{
${ }^{5}$ First three year period 2009-2011, second three year period 2013-2015, one edition per year.

${ }^{6}$ The current number of established Italian provinces is 110 . The lower number analysed in the RCAU Report (103, according to the 1992 ordination) let the model run through homogenous time series.

${ }^{7}$ Istat, Istituto Tagliacarne, Agenzia del Territorio, Il Consulente Immobiliare, Miur, Espon, Corine Land Cover, ecc. are just some of the several data sources introduced in the evaluation model. The data selected had to satisfy criteria such as public diffusion, geographical scale (NUTs-3 level: "provinces") and time series uniformity (from 1995 or 2000).
} 
The standard aggregation procedure works by means of an automatic weighting process ${ }^{8}$, useful to sum together at each aggregation level the standardised rating ${ }^{9}$ [12].

Where:

$$
\mathrm{I} \hat{n} d_{j}^{s}(t)=\sum_{j=1}^{h} \mathrm{I} \hat{n} d_{p j}^{s}(t) p_{j}(t)
$$

- $\quad \operatorname{In} d_{j}^{1}(t)$ is the $j$-th standardised indicator for each of the 110 "province" at time $t$, among the $\mathrm{h}$ indicators gathered under the sub dimension $s$;

- $\quad p_{j}(t)$ is the weight associated to the $j$-th indicator, so that:

$$
\sum_{j=1}^{h} p_{j}(t)=1
$$

Thus, Italy has been mapped in a geo-referred image at NUTs 3 level (see fig. ${ }^{\circ} 1$ ).
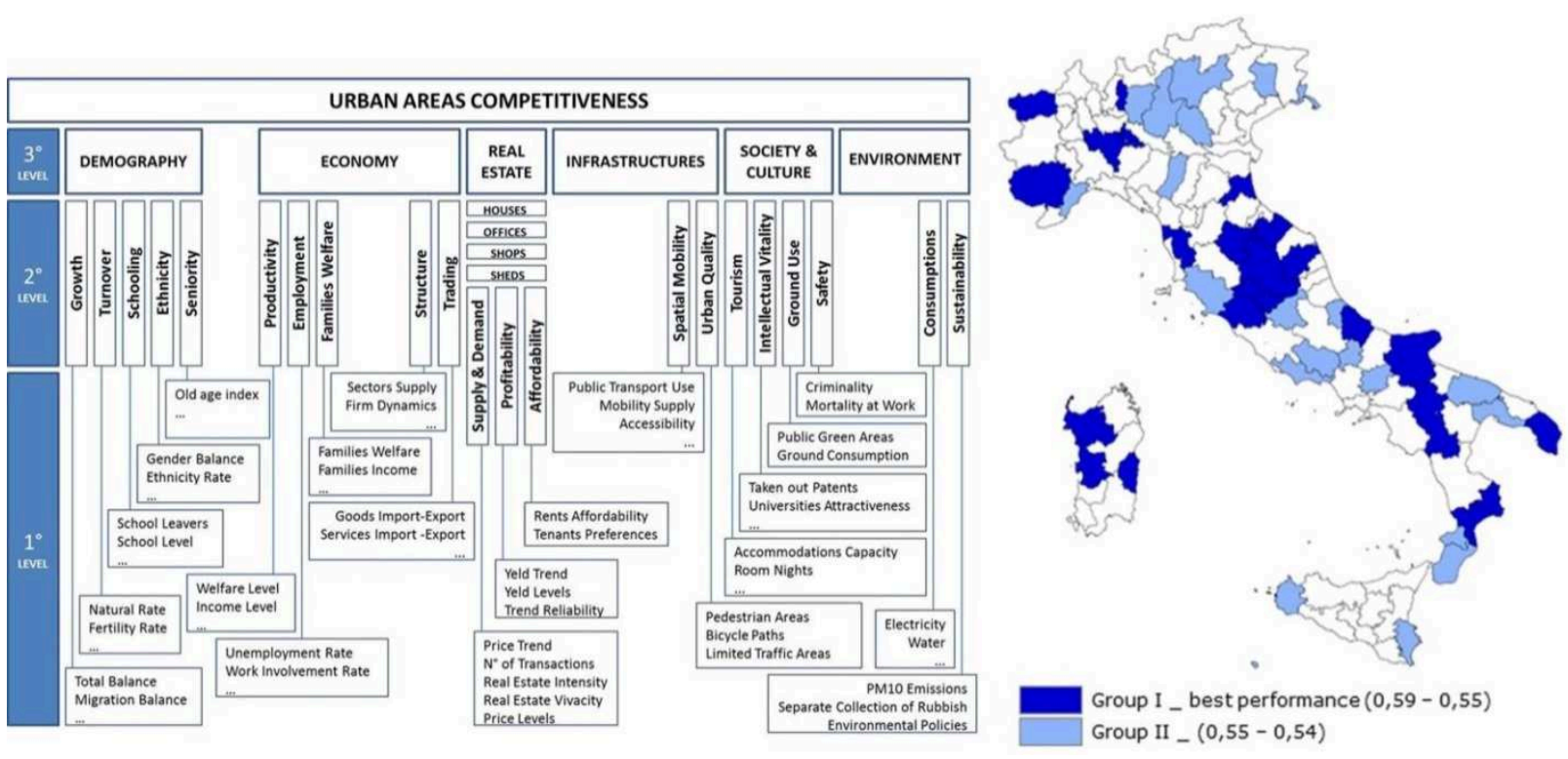

Fig. 1 Structure of the indicators used in the model of the macro analysis and the GIS image of housing competitiveness - reference year 2013

The focus on the Area Vasta of Cagliari ${ }^{10}$ starts from a reasoning on some specific variables we selected as the key-comparison elements among the 110 urban areas of the national Report.

In 2012 a Strategic Plan for the Area Vasta of Cagliari ${ }^{11}$ urban area in the southern coast of Sardinia, has been launched. It involves nearly 420,000 inhabitants to share a common development vision within a wide territory where the seaside as well as the rural, natural and touristic aspects are merged with the industrial and urban image of the main city. Aware that the natural conflicts at the local level may be better solved if the inner mechanism of the local resources allocation is properly analysed and unveiled, the Sardinia Region requested the EIB to produce a competitiveness analysis focused on the Area Vasta of Cagliari along with the 2013 RCAU Report. Here a part of this study

\footnotetext{
${ }^{8}$ The Report explicates the automatic weighting process calculation in the methodological section, a digital source document attached to each Report edition, available on demand by the authors.

${ }^{9}$ To define the weight to be associated to each h-indicator belonging to each s-sub dimension, the model works through correlation matrixes. The methodology is automatic and replicable for each $\mathrm{j}$-th indicator and for each level of the three-shape aggregation scheme shown in fig. ${ }^{\circ} 1$.

${ }^{10}$ The Area Vasta of Cagliari has been defined by the Memorandum of Understanding signed the $13^{\text {th }}$ of December 2005 by the municipalities mayors of Cagliari, Quartu Sant'Elena, Assemini, Elmas, Decimomannu, Pula, Sarroch, Villa San Pietro, Capoterra, Quartucciu, Maracalagonis, Sinnai, Settimo San Pietro, Selargius Monserrato e Sestu.

${ }^{11}$ This is an urban instrument signed with Municipal Resolution: 65/2012.

http://www.comune.cagliari.it/resources/cms/documents/AreaVasta_PianoStrategicoIntercomunale_DelibereApprovazioneComuniPr ovince.pdf.
} 
is presented, mainly related to the real estate prices, intended as a good economic sampling equipment, in line with the welfare economy theory (Goodman, 1978 [13]; Freeman, 1993 [14]; Realfonzo, 1994 [15]), with reference to those external components (positive or negative, material or immaterial) driving the market. Thus, a matrix made of 80 standardised variables and 110 provinces has been produced, on which we calculated the Euclid distances:

$$
\mathrm{D}_{\mathrm{j}}=\sqrt{\sum_{i}\left(Z_{i, \text { Cagliari }}-Z_{i, j}\right)^{2}}
$$

The minimum Euclid distances carried out from the matrix let us discover that Cagliari can be included in a cluster together with Varese, Novara, Genoa, La Spezia, Modena and Palermo.

These urban areas reveal the nearest competitiveness RCAU rating ${ }^{12}$ even if three real estate residential variables (here represented by means of real data - see fig. 2) present remarkable ratings. The variables are: price levels of new stock $^{13}$, dynamic of the number of transactions per year, percentage variation of the housing stock in terms of new buildings or renewal operation yearly registered.
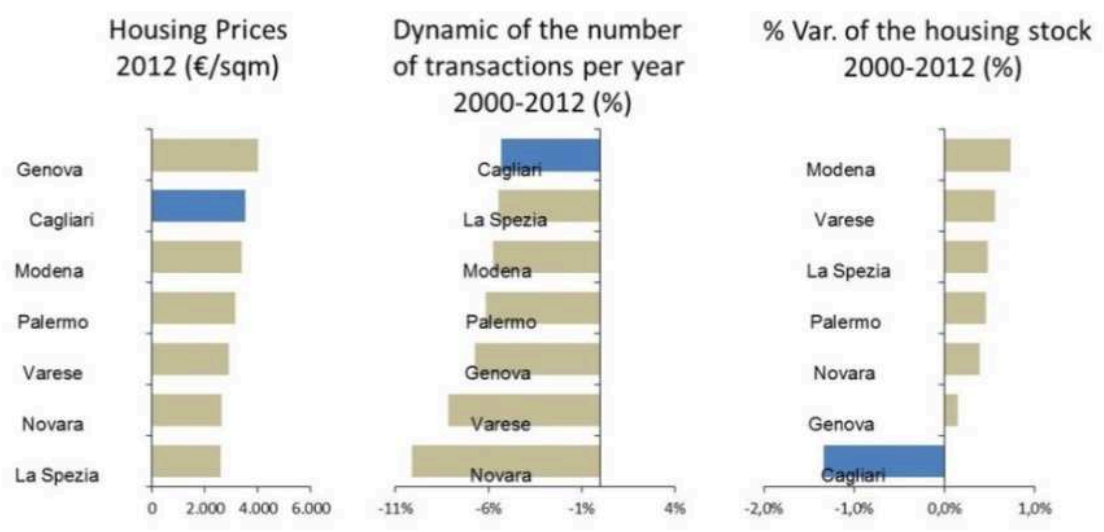

Fig. 2 The rating of the three residential real estate variables selected for the cluster.

The fact opens some interrogatives as, while the macro dataset informs us about the Sardinia and Cagliari population reduction (common to the cluster in general, mainly due to a low generation turnover and low immigrates integration), in Cagliari the housing demand seems to increase and prices are quite high.

It could be derived that the demand pressure is high but probably the quality of the housing stock is not. Infect during the last 10 years Cagliari city has lost nearly $9 \%$ inhabitants, moved towards the 15 surrounding municipalities $(+8 \%)$ - see fig. 3 for the detailed data on the $\%$ variations registered between 2001-2011.

Among the municipalities bordering with Cagliari, Quartu Sant'Elena is the one more similar for demography dynamics and real estate prices $(-23 \% € / \mathrm{sqm}$ compared to Cagliari). The continuity is interrupted in Maracalagonis and Sinnai, due to the highway 554 infrastructural barrier, and to the presence of industrial areas.

A different impact has the state highway 131, linking Cagliari on its north-west side to the city airport. Along this highway an important commercial and service network has been developed, just near Elmas-Assemini and Sestu. The demographic analysis, based on the differences between the last two Italian population census data (Istat, 2001; Istat 2011), evidences that the most relevant demographic increases have been registered from 2001 to $2011^{14}$, just in these municipalities: $+31 \%$

\footnotetext{
${ }^{12}$ The Report shows both a general rating for each competitiveness dimension and specific ratings for the 110 different provinces.

${ }^{13}$ The data used in the macro RCAU dataset refers to the "Il Consulente Immobilare", a periodical magazine published by the main economical editor "Il Sole24Ore". The new stock real estate prices have been used.

${ }^{14}$ Fondazione ISMU elaborations on ISTAT data (Istat- Italian National Institute of Statistics, 2001 census data; Istat- Italian National Institute of Statistics, 2011 census data).
} 
in Sestu, $+13 \%$ in Elmas. Moreover, regarding Sestu, Monserrato and Selargius, the main determinant of the residential prices is probably the presence of the "Cittadella Universitaria" and the adjacent General Hospital of Monserrato. Another major element is likely to be the light railway connecting Cagliari to Monserrato-Selargius ( $5 \mathrm{Km}$ from Cagliari) where recently new dwellings have been built, and the population density doubles the one in Cagliari (3.200 inhab./sqKm).
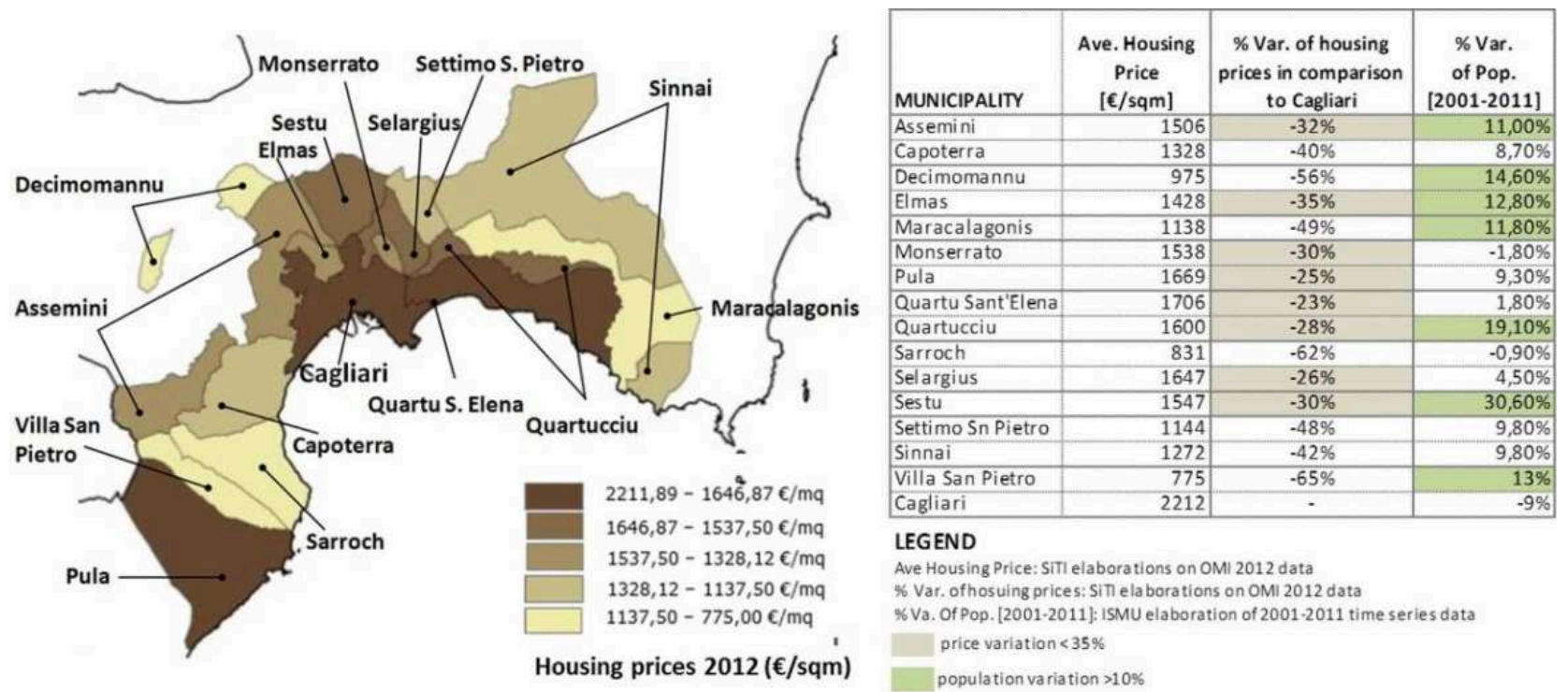

Fig. 3 Housing prices and demographic trend in the Area Vasta of Cagliari

The real estate prices decrease up to $-65 \%$ towards west (Capoterra, Sarroch and Villa San Pietro) not only because of the distance from Cagliari, but also for the presence of the petrochemical industries.

Pula, the farer municipality from Cagliari, deserves an in depth analysis because of its high real estate potential, where prices seldom exceed the Cagliari ones, especially for its second homes stock, which, on average, overcomes the $2,200 € / \mathrm{sqm}$. The average values of the ordinary stock reveal only a $-25 \%$ compared to Cagliari.

\section{Conclusions}

The systemic analysis on macro and micro data contributes to develop some final remarks on potential measures to adopt in order to contrast contingent threats or just to sustain the existing opportunities. The progressive demographic depletion of Cagliari in favour of its surroundings is probably pulling the real estate pricing to increase in all the hinterland, but a relevant question regards the quality of the residential stock not only in Cagliari.

At the same time the whole Area Vasta is probably growing as a polycentric hinterland.

To support the development of a sustainable metropolitan area, infrastructures, mobility, quality of life and environmental performances need then to be enhanced.

To sum up:

- the most high real estate prices are polarised along the coast (Cagliari and Quartu in the urban area, where more services and mobility are provided, or in Pula, towards the rural territory, where the attractiveness derives from natural-touristic resources;

- high real estate prices are registered in municipalities where recently the Cagliari population has moved (Elmas, Assemini, Sestu). These municipalities are provided with a good mobility;

- the major price contractions are referred to industrial areas or where the population density is over the 3,000 inhab./sqKm. (Villa San Pietro, Sarroch-Sinnai-Maracalagonis);

- an open question deals with the re-powering of Cagliari central areas. The new stock reveals in fact mid-high prices, today even increasing on average of $+3,3 \%$ a year (a counter-trend in 
comparison to the expected short time dynamics, comprised between $-3 \% / 1,1 \%$ ). It means that it should be of strategic interest to speed up the renewal process on the housing stock;

- if northern municipalities such as Monserrato and Selargius, even providing the local market with a recently built housing stock in direct connection with Cagliari, do not express high values, it seems reasonable to suggest a further insight to define a proper strategy to improve the local life quality;

- the mid-high selling prices registered in Pula need to be monitored: if the next generations should prefer to invest their family savings out of the region (as the current trend is foreseeing) they could prefer to sell off the second hand assets, causing their value to abruptly decrease. A possible strategy may be related to incentives to maintenance costs, retrofitting interventions, in order to motivate the natives not to disinvest in the area.

\section{References}

[1] Information on http://ec.europa.eu/regional_policy/thefunds/instruments/jessica_en.cfm.

[2] Sinloc, Fondazione Ismu, SiTI, Prometeia: Rapporto di Competitività delle Aree Urbane Italiane 2008, Tipografia Compositori, Bologna, Giugno 2009

[3] Sinloc, Fondazione Ismu, SiTI, Prometeia: Rapporto di Competitività delle Aree Urbane Italiane 2009, Padova, Giugno 2010

[4] Sinloc, Fondazione Ismu, SiTI, Prometeia: Rapporto di Competitività delle Aree Urbane Italiane 2010, Padova, Giugno 2011

[5] Sinloc, Fondazione Ismu, SiTI, Istituto Tagliacarne: Rapporto di Competitività delle Aree Urbane Italiane 2012, Padova, Dicembre 2013

[6] A. Smith: An Inquiry into the Nature and Causes of Wealth of Nations, (1776)

[7] D. Ricardo: Principles of Political Economy and Taxation, cap.7, (1817)

[8] K. J. Arrow: The Economic Implication of learning by doing, Review of economic studies, $\mathrm{n}$. 29, (1962)

[9] F.A. Hayek: Law, Legislation and Liberty, A New Statement of the Liberal Principles of Justice and Political Economy. London, Routledge and Kegan Paul, (1976)

[10] WCED-World Commission on Environment and Development, Report of the Brundtland Commission: Our Common Future, Oxford University Press, (1987)

[11] United Nations, Kyoto Protocol to the United Nations Framework Convention on Climate Change, Kyoto, (1997)

[12] F. Bodano, L. Ingaramo, S. Sabatino: The Urban Areas Competitiveness Report (RCAU): an information system to support the JESSICA revolving funds in Italy, in "Planning Support Tools: Policy Analysis, Implementation and Evaluation Proceedings of the Seventh International Conference on Informatics and Urban and Regional Planning INPUT 2012" (by di M. Campagna, A. De Montis, F. Isola, S. Lai, C. Pira, C. Zoppi) (2012)

[13] A. C. Goodman: Hedonic prices, price indices and housing markets, Journal of Urban Economics 5, (1978), pp. 471-484

[14] A. M. Freeman: The measurement of environmental and resource values: theory and methods, Washington (D.C.), Resources for the Future, (1993)

[15] A. Realfonzo, Teoria e metodo dell'estimo urbano, Nis, Roma (1994) 